\title{
An Empirical Study on Travelers' Acceptance Intention of Travel Information on Social Networks
}

\author{
Jian Chen $\mathbb{D}^{1},{ }^{1}$ Rui Li $\mathbb{D}^{1},{ }^{1}$ Zhiyan Fu, ${ }^{2}$ Chi Zhang, ${ }^{1}$ and Fatao Yuan ${ }^{1}$ \\ ${ }^{1}$ College of Traffic and Transportation, Chongqing Jiaotong University, Chongqing 400074, China \\ ${ }^{2}$ School of Economics and Business Administration, Chongqing University of Education, Chongqing 400067, China \\ Correspondence should be addressed to Jian Chen; chenjian525@126.com
}

Received 12 July 2020; Revised 6 November 2020; Accepted 16 November 2020; Published 21 November 2020

Academic Editor: Haoran Zhang

Copyright (c) 2020 Jian Chen et al. This is an open access article distributed under the Creative Commons Attribution License, which permits unrestricted use, distribution, and reproduction in any medium, provided the original work is properly cited.

Social networks are new channels for travelers to obtain or share travel information, which has important impacts on their travel decision-making behavior. Therefore, the psychological feelings of travelers and their acceptance intention (AI) of this type of travel information should be explored. In this study, certain psychological latent variables were incorporated into a technology acceptance model to construct an extended model that explores the factors influencing the travelers' AI of travel information on social networks. This model was validated using survey data collected in Chongqing, China. The influence of each factor on the AI and the interaction between factors were quantitatively described using the structural equation modeling method. The results showed that the perceived risk, perceived trust, and perceived usefulness are the most important factors affecting travelers' AI; the subjective norm, hedonic motivation, and perceived ease of use also exert a certain degree of influence; the proposed research model has a good interpretation ability for AI, and the explanatory power has reached $52 \%$. This study confirmed the applicability of the constructed model in this research field on the basis of survey data and provided a theoretical reference for ascertaining the attitude of travelers toward travel information available on social networks.

\section{Introduction}

With the development of information technology and the popularization of smart terminal devices, the way people use the Internet has gradually shifted from simple information search and web browsing to information interaction based on social media. Thus, social media has become an important service platform for people to publish, acquire, and disseminate information. According to the Global Digital Report of 2020 [1], the number of Internet users worldwide is 4.54 billion and the number of active social media users is 3.80 billion. The social media platforms Facebook, YouTube, and WhatsApp are ranked as the top three globally, with $2.45,2$, and 1.6 billion active users, respectively. Chinese social media platforms WeChat, QQ, Qzone, and Sina Weibo are also ranked among the top ten in the world by a number of active users. Social networks are related to the Internet based on the social relationship between social media users, that is, "Social+Internet". The rapid development of social networks has shortened the spacetime distance of information, endowed it with higher value, and gradually created an ecosystem that "connects everything". People can express opinions, make friends, interact with them, and obtain information conveniently and quickly on the social network, thus generating a large amount of information that has an important influence on people's daily life behavior patterns $[2,3]$.

The mass information on social networks also involves a significant amount of travel information. The content of travel information on social networks mainly includes two types: one is the information obtained by the traveler via social media during the travel process, concerning the traffic system, such as road conditions, transit time, accidents, and weather information; the other concerns information on related experiences shared by other travelers regarding travel destinations, travel modes, and travel route decisions [4-7]. This information can be sent out in the form of a Twitter message, discussion post, WeChat moments, or Sina Weibo 
message. The information content can be presented in various forms, such as text, pictures, video, or voice. The source of the travel information can be the official social media account of the traffic management department or the personal social account of the traveler. This travel information has an important influence on the travel decisionmaking behavior of travelers. It can affect people's attitudes regarding travel plans, allowing them to prejudge the travel environment before travel. It can also affect the optimization and adjustment of travel routes during travel and update and share the travel experience after travel. Travel information on social networks is qualitatively different from the travel information published on traditional channels such as TV and radio. It has a faster propagation speed, higher timeliness, wider coverage, and stronger interactive function between the publisher and the receiver. It also has obvious advantages compared with location-based service map applications, such as Google Maps, Gaode Maps, and Baidu Maps. The information content is richer, the release form is more diverse, the timeliness is higher, the trust of the traveler is higher, and the interactive function between the publisher and recipient of the travel information is also stronger. It should be noted that social networks are used as supplementary channels for obtaining travel information other than traditional channels, such as television and radio, and location-based map applications, such as Google Maps and Gaode Maps, rather than an alternative channel. Travel information on social networks has new information content, new release modes, and new dissemination efficiency, which makes residents' travel decision-making into a multidimensional information environment.

In recent years, scholars have gradually discovered that there exists a significant relationship between travel information on social networks and decision-making behavior. De Abreu e Silva et al. conducted an online survey of college students in the three cities of Lisbon, Granada, and Zagreb and explored the relationship between information and telecommunication technologies (ICT), social media use, and travel mode choice behavior. Then, they analyzed the cross-cultural differences within the surveyed population [8]. Khan et al. explained the impact of the use of transportsupport applications and social networks on weekend travel behavior through online survey data collected in Halifax, Canada. They also considered the moderating effect of travelers' personal attributes such as age and gender [9]. Chen and Deng conducted a survey on residents in some cities in China and used the hierarchical clustering analysis method to find the relationship between information use, social networks, and cooperation awareness in the traveler's choice of travel mode [10].

The premise for travel information to be widely disseminated on social networks and influence travel decisionmaking behavior is that travelers must be willing to share and accept this information. Researchers have begun to explore the influencing factors on travel information sharing behaviors on social networks in recent years, but they have rarely considered the influencing factors on the travelers' acceptance behavior. Bilgihan et al. considered that factors such as subjective norms, utilitarian beliefs, and perceived ease of use have a significant impact on travelers' willingness to share travel information on social networks [11]. Oliveira et al. found that perceived enjoyment, security, and privacy are important influencing factors for travelers to share travel information and experience on social networks [12]. On this basis, Oliveira et al. further pointed out the relationship between altruistic motivations, personal fulfillment, and selfactualization, and their impact on travelers' willingness to share travel information on social networks [13]. Information sharing and information reception are both important links of travel information dissemination on social networks; thus, the factors influencing their acceptance behavior are also worth discussing. Chung et al. found that argument quality, source credibility, perceived usefulness, and social relations are the decisive factors affecting travelers' acceptance of travel information on social networks [14]. Berhanu and Raj investigated the degree of international tourists' trust in travel information on social networks and analyzed the demographic attributes of age, gender, and education [15].

Although a small number of studies have begun to focus on the acceptance of travel information on social networks, these studies are still in their infancy, and the impact factors considered therein are limited. The subjective attitude of travelers to the acceptance of travel information on social networks is not yet clear. Thus, in this study, an analysis model of the intention to accept travel information on social networks was constructed based on the technology acceptance model. It aims to quantitatively describe the psychological feelings of travelers toward the travel information on social networks and explain the influence process of various influencing factors on the acceptance intention. The research outcomes are expected to provide decision-making references for publishers, policy makers, and operation managers of travel information on social networks, thereby aiding them in the provision of better, more accurate, and more acceptable travel information for travelers. This is one of the few studies in this field.

The remainder of this paper is organized as follows. In Section 2, the research hypotheses of this study are proposed on the basis of the technology acceptance model (TAM) and related theories. In Section 3, the research survey design, variable measurement, and data analysis methods are introduced. In Section 4, the data analysis results of the research model are presented. In Section 5, the impacts of model variables on the AI of travel information on social networks are compared and analyzed against the research findings of other studies. In Section 6, the theoretical and practical significance of this study is summarized, and the limitations of the current study and the future research directions are also noted.

\section{Theoretical Model and Research Hypothesis}

\subsection{Basic Theory and Model}

2.1.1. TAM Model. Many theoretical models have been developed in the research fields of sociology and psychology to analyze and explain the public's acceptance of certain 
technology or information. The most widely used model is the TAM. In 1989, Davis proposed the TAM [16] in conjunction with the theory of reasoned action (TRA) while exploring the factors that influence users' usage behavior of information systems. The TAM considers that the behavioral intention (BI) plays a decisive role in the actual behavior $(\mathrm{AB})$ of the user, and the $\mathrm{BI}$ is affected by the attitude, perceived usefulness (PU), and perceived ease of use (PEU). The model conceptual framework of the TAM is shown in Figure 1. PU reflects the degree to which an individual believes that using the information system would improve his/her job performance. PEU reflects the degree of ease that an individual feels while using an information system. Attitudes refer to the individual's positive or negative subjective feelings when using an information system. The TAM applied the TRA to the field of technology acceptance research for the first time. It deeply analyzed the process of users' intention and the usage behavior of information systems. It has a strong ability to explain the relationship between core variables such as attitude, $\mathrm{BI}$, and $\mathrm{AB}$.

The TAM is a powerful theoretical tool for predicting and explaining the acceptance of information technology by individuals or organizations. It has been widely used in research for exploring various aspects such as social behavior, learning behavior, and business behavior. However, because the original variables were designed to analyze users' acceptance of information systems, the research in other fields has to expand the influencing factors when utilizing the TAM, thereby enhancing its applicability in the new research field [17-20]. The social media platform that can obtain travel information is essentially an information system, and hence, the TAM can be used as the basic theoretical framework for this study to analyze the AI of travel information on social networks.

2.1.2. Other Classical Theories. Other classic theories in the field of personal behavior research also provide support for the variable design of this research theoretical model, such as perceived risk, perceived trust, hedonic motivation, and rational behavior theory.

Perceived risk was originally a concept extended from the field of psychology by Bauer [21] of Harvard University in 1960. Bauer believes that an individual's behavior may not be able to determine whether the expected result is correct and certain results may make him feel unpleasant. Therefore, this implicit uncertainty in the outcome of a decision is the initial concept of perceived risk. When Bauer introduced this concept, he emphasized that perceived risk concerns subjective (perceived) rather than objective (real world) risk and further divided perceived risk into the uncertainty of decision results and severity of consequences of wrong decisions.

Perceived trust is derived from trust theory. Mayer et al. [22] defined trust as the belief that an individual is willing to believe the corresponding characteristics of other people or things and is willing to take risks. The extended TAM model proposed by Gefen et al. [23] also takes trust as a core variable, laying a foundation for the combination of trust and TAM. Since the social network is a virtual environment, the degree of uncertainty and security risk of travel information in it is higher than that in the traditional environment; thus, trust has become an important factor to consider.

Subjective norm is derived from the theory of rational behavior [24], which refers to the social pressure that an individual feels regarding whether to take a particular behavior or refers to the influence of the individuals or groups on the individual's behavioral decision-making. Venkatesh and Davis [25] introduced subjective norm variables in the extended model of the TAM.

Hedonic motivation refers to the user's willingness to initiate behaviors that can enhance positive experiences (pleasure, happiness, etc.) and reduce negative experiences (frustration, sadness, etc.). It is used to explain the general principle of personal behavior. The principle is that individuals are more likely to initiate behaviors that lead to rewards or away from punishment [26]. Hedonic motivation has been proven by research for its important role in the field of technology acceptance [27] but, in the field of technology acceptance, Venkatesh et al. conceptualized hedonic motivation as the perceived fun and joy of using a certain information technology system [28].

2.2. Research Hypothesis. In this study, to better explain the traveler's AI of travel information in the social network and explore the corresponding influencing factors, an analysis model of the AI for travel information in the social network is constructed based on the TAM. In this model, the AI, PU, and PEU are borrowed from the original TAM, and the subjective norm ( $\mathrm{SN})$ is borrowed from the TRA and the extended TAM $[24,25]$. On considering the new mode and content of travel information on social networks, travelers will make subjective cognitive judgments about the risk, trust, and interest in it. Therefore, the three variables of perceived risk (PR), perceived trust (PT), and hedonic motivation (HM) are added in this study, after referring to the relevant theories, to enhance the applicability of the constructed model for the analysis of the AI of travel information on social networks. The model research hypothesis and conceptual framework are shown in Figure 2.

2.2.1. Acceptance Intention (AI). An important concept of the TAM is to reflect the $A B$ with $B I$, and its effectiveness has been extensively demonstrated [29-31]. The AI in this study indicates the traveler's willingness to use or recommend others to use the travel information in the social network. It is a behavioral intention that reflects the willingness to accept. Thus, AI can be used as a dependent variable for various influencing factors in the study to explore the traveler's acceptance of travel information on social networks.

2.2.2. Perceived Usefulness (PU) and Perceived Ease of Use $(P E U)$. Both PU and PEU come from the TAM [16]. PU here indicates the travelers' perception of job performance 


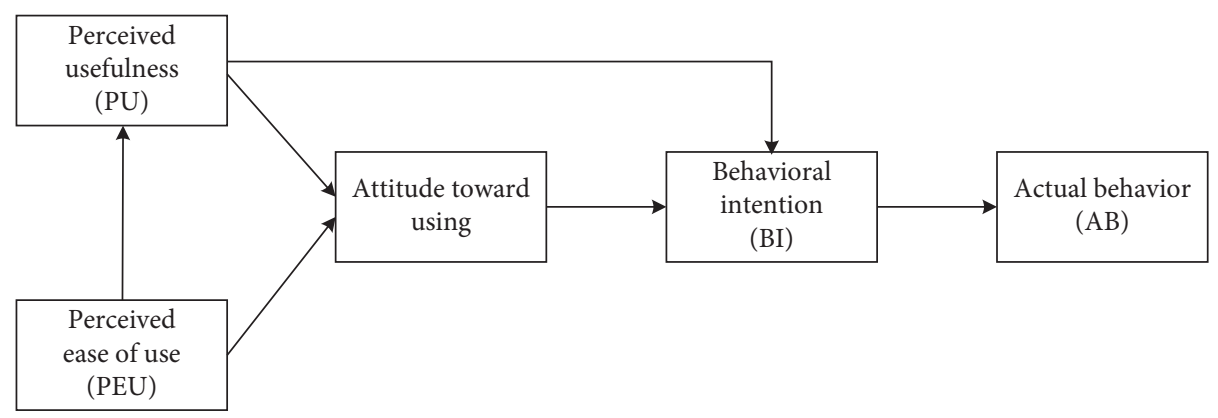

Figure 1: Conceptual framework of TAM.

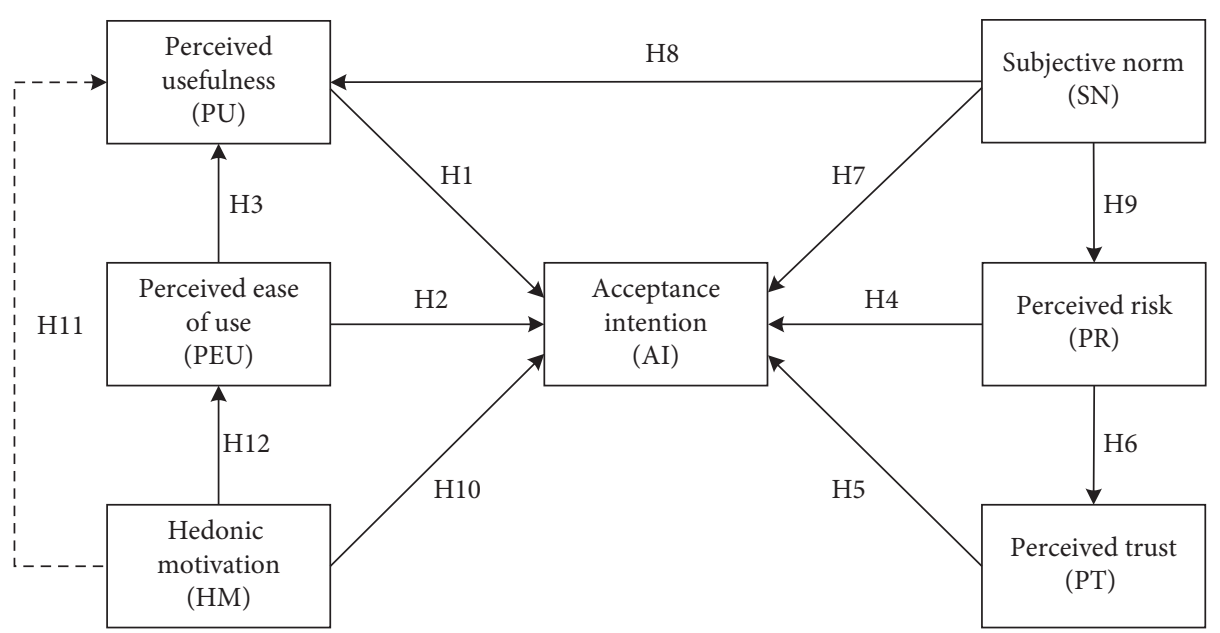

FIGURE 2: Research hypothesis and the conceptual framework of the model.

improvement using travel information on social networks, and PEU refers to the travelers' cognition of the ease of using a social network media platform (Facebook, YouTube, Sina Weibo, WeChat, etc.) to obtain the travel information. The greater the benefits of accepting travel information on social networks and the simpler the operation process of using social network media platforms to obtain travel information, the more likely the travelers will accept this information. At the same time, the TAM pointed out that the PEU will positively affect the PU. Therefore, the following hypotheses are formulated:

H1: PU has a positive impact on the AI of travel information on social networks.

$\mathrm{H} 2$ : PEU has a positive impact on the AI of travel information on social networks.

H3: PEU has a positive impact on PU.

2.2.3. Perceived Risk (PR) and Perceived Trust (PT). PR refers to the individual's perception of uncertainty about the outcome of a decision [21]. It here refers to the traveler's awareness of the risks in terms of time, cost, and personal privacy created by travel information on social networks. Travelers show significant risk aversion when making behavioral decisions. The higher the risk of travel information on social networks is, the less willing they are to accept it. PT comes from the expansion of the TAM by Gefen et al. [23]. It here refers to travelers' belief that the travel information on social networks will not affect their own interests. The higher the degree of trust in the travel information on social networks is, the higher the travelers' willingness to accept it. At the same time, the higher is the risk perceived by travelers of the travel information on social networks, the lower their degree of trust in the information is. Therefore, the following hypotheses are formulated:

H4: PR has a negative impact on the AI of travel information on social networks

H5: PT has a positive impact on the AI of travel information on social networks

H6: PR has a negative impact on PT

2.2.4. Subjective Norm (SN) and Hedonic Motivation (HM). $\mathrm{SN}$ is considered from the TRA proposed by Fishbein and Ajzen and the extended TAM proposed by Venkatesh and Davis $[24,25]$. It here represents the influence of relatives, friends, and colleagues close to the travelers on their own behavior decisions. Social networks are essentially built on the basis of social relationships among users; thus, travelers' decision-making behavior will be influenced by social groups such as relatives, friends, and colleagues. The greater the positive impact is, the easier it is for travelers to accept 
the travel information on social networks. At the same time, the PU and PR of the travel information on social networks by relatives, friends, and colleagues in the surroundings will also directly affect the traveler's perception of these two variables. HM refers to the user's expectation of using information or technology to enhance positive experiences (pleasure, happiness, etc.) and reduce negative experiences (frustration, sadness, etc.). The importance of the role of HM has been proven in the field of technology acceptance $[26,27]$. However, Venkatesh et al. have conceptualized HM as a perception of the fun and joy of using an information technology system in the field of technology acceptance research [28]. HM here refers to the traveler's perception of the degree of interest and joy of using social networks to obtain travel information. The higher the level of interest and joy the information provides, the stronger the AI of the traveler will be. At the same time, if the traveler is in a happy mood, the stronger the PU and PEU of the travel information on social networks will be. Consequently, the following hypotheses are formulated:

H7: SN has a positive impact on the AI of travel information on social networks

H8: SN has a positive impact on PU

H9: SN has a positive impact on PR

H10: HM has a positive impact on the AI of travel information on social networks

H11: HM has a positive impact on PU

H12: HM has a positive impact on PEU

\section{Methods}

3.1. Survey Design. In this study, the residents of Chongqing were selected as the survey targets, and a combination of online and offline questionnaires was randomly distributed to investigate the AI of travel information on social networks. The online questionnaire is distributed through the "Questionnaire Star" network platform, and the network link is shared through social software, such as Sina Weibo, WeChat, and QQ. The area of the offline survey was selected in the business districts, bus stations, rail stations, etc., of the central city's administrative districts, where there were many people and travel, and the samples were obtained in the form of random interviews by investigators to ensure the randomness of the sample collection and reduce bias.

In the questionnaire, a brief textual introduction of travel information on social networks and the corresponding characteristics of their access platforms (Facebook, YouTube, Sina Weibo, WeChat, etc.) was given at the beginning. The survey comprised two parts. The first part gathered the demographic characteristics, including gender, age, education level, monthly income, and ownership of a private car. The second part included a measurement scale for the travelers' subjective perceptions of travel information on social networks, covering the measurement of seven variables, namely, PU, PEU, PR, PT, SN, HM, and AI. On the basis of the designed measurement scale, the reliability and validity of the questionnaires were examined using the data collected via a small sample pretest. The measurement items that failed in the test were removed to obtain the final and formal questionnaires. After the testing process, it took approximately 5 to $10 \mathrm{~min}$ to complete one questionnaire. The survey was conducted in October 2019 in Chongqing, where 500 copies (100 copies of the online questionnaires and 400 copies of the offline) of the formal questionnaire were issued within two weeks.

3.2. Research Measurement. The five-point Likert scale was adopted in this study to measure the latent variables that cannot be directly observed in the model. To reflect the travelers' psychological feelings about travel information on social networks, a 5-point score-from "strongly disagree $(=1)$ " to "strongly agree $(=5)$ " - was used to rank the respondent's degree of approval toward the relevant description given in each questionnaire measurement item. The measurement items for each variable were adapted accordingly based on previous research in the field of technology acceptance. The specific measurement items are detailed in Table 1.

\subsection{Data Analysis}

3.3.1. Introduction of Method. To simultaneously explore the influence relationships between latent variables-that are relatively abstract in concept and cannot be measured directly-the structural equation modeling (SEM) method, a multivariate statistical analysis technique, was applied to analyze the data. The parameter estimation method used in this study is the maximum likelihood method, and the package software Mplus7.4 is used for the corresponding calculation. The SEM method can analyze the relationship between multiple dependent variables at the same time, and it has been widely applied in psychology, pedagogy, sociology, and other research fields [32-34]. The structural equation model is divided into two parts: a measurement model and a structural model $[35,36]$. The measurement model is used to describe the relationship between explicit variables and latent variables, and the structural model is used to describe the relationship between latent variables. The basic equations are as follows:

$$
\begin{aligned}
& X=\Lambda_{X} \xi+\delta, \\
& Y=\Lambda_{Y} \eta+\varepsilon, \\
& \eta=\mathrm{B} \eta+\Gamma \xi+\zeta .
\end{aligned}
$$

Among them, equations (1) and (2) represent the measurement model, and equation (3) represents the structural model. $\xi$ and $\eta$ are vectors composed of exogenous latent variables $(\mathrm{SN}, \mathrm{HM})$ and endogenous latent variables (PU, PEU, PR, PT, AI), and $X$ and $Y$ are the observed variables of $\xi$ and $\eta$ (measurement item). $\Lambda_{X}$ and $\Lambda_{Y}$ are the factor loading coefficient matrices of $X$ and $Y$, respectively; $B$ is the path coefficient matrix between endogenous latent variables; $\Gamma$ is the path coefficient matrix between exogenous 
TABLE 1: Measurement items for model variables.

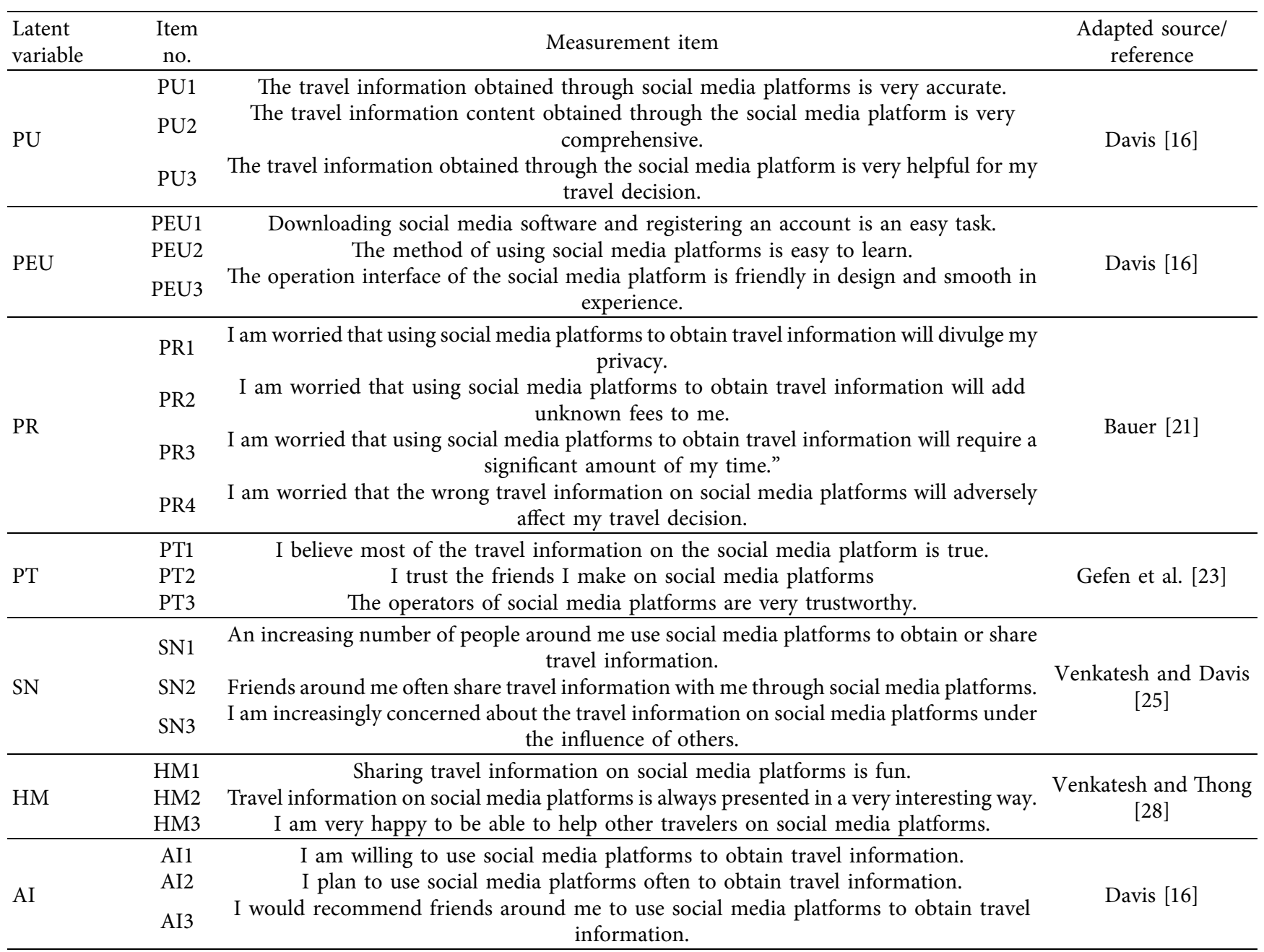

latent variables and endogenous latent variables, $\delta$ and $\varepsilon$ are the measurement errors of the observed variables, and $\zeta$ is the model residual, which represents the part that $\xi$ cannot explain or predict for $\eta$. It is worth noting that $\delta$ has no correlation with $\xi, \eta$, or $\varepsilon$. Furthermore, $\varepsilon$ has no correlation with $\xi$, $\eta$, or $\delta$.

The reliability and validity of the model need to be tested using the confirmatory factor analysis (CFA) method [37]. CFA is often tested using the SEM method. The analysis process is the quality inspection process of the measurement model in the structural equation model. The main inspection indicators include factor loading coefficient $\lambda$, construct reliability (CR), and average variance extracted (AVE). The calculation equations for $\mathrm{CR}$ and $\mathrm{AVE}$ are as follows:

$$
\begin{aligned}
\mathrm{CR} & =\frac{\left(\sum \lambda\right)^{2}}{\left[\left(\sum \lambda\right)+\sum \theta\right]}, \\
\mathrm{AVE} & =\frac{\sum \lambda^{2}}{\left[\sum \lambda^{2}+\sum \theta\right]},
\end{aligned}
$$

where $\lambda$ is the factor loading coefficient of the observed variable and $\theta$ is the measurement error of the observed variables ( $\delta$ and $\varepsilon$ ). Both $\lambda$ and $\theta$ can be directly calculated via Mplus software, as well as CR and AVE can be calculated via (4) and (5).

3.3.2. Evaluation Criteria of Quality. At the same time, to ensure the validity of the questionnaire design and the adaptability of the constructed model, the reliability and validity of the model and its overall goodness-of-fit need to be tested through the data obtained from the questionnaire survey.

The reliability and validity of the questionnaire reflect the inherent quality of its model. The reliability test typically examines the internal consistency of the questionnaire measurement items, which is usually evaluated using the construct reliability (CR). The evaluation criteria (threshold) adopted by Kline and many other researchers [35, 38, 39] are as follows: a CR value of above 0.9 indicates the best results, 0.8-0.9 indicates very good results, $0.7-0.8$ indicates moderate results, and $0.5-0.7$ indicates acceptable results. The validity test generally examines the two aspects of convergent validity and discriminant validity. If the factor loading coefficient of each measurement variable exceeds 0.6 , and the average variance extracted (AVE) is greater than 0.5 , the 
model has a good convergent validity [40]. According to the evaluation criteria proposed by Fornell and Larcker [37], if the square root of the AVE of each latent variable is greater than the Pearson correlation coefficient (PCC) between this variable and the other variables, the model has good discriminant validity.

The covariance matrix of measurement variables generated via quantitative parameter estimation was tested for its closeness to the sample covariance matrix. The better the model fits, the more accurate the parameter estimation is. The model's overall goodness-of-fit indices [35, 41, 42] include the chi-square degree of freedom ratio $\left(\chi^{2} / \mathrm{d} f\right.$, also known as standard chi-square), root mean square error of approximation (RMSEA), comparative fit index (CFI), nonnormed fit index (NNFI, also known as the TuckerLewis Index, TLI), and standardized root mean square residual (SRMR). Kline pointed out that for a good model fit, the goodness-of-fit indices should meet the following criteria: $\chi^{2} / \mathrm{d} f$ is in the range of $1-3$, CFI and TLI are greater than 0.90 , and RMSEA and SRMR are less than $0.08[35,43]$.

\section{Results}

4.1. Questionnaire Statistics. After invalid questionnaires-i.e., those that had not been filled in carefully, had more than three missing values, and selected more than five extreme values consecutively-were eliminated, a total of 429 valid questionnaires (93 online questionnaires and 336 offline questionnaires, with a ratio of approximately 1 : 3.6) were recovered, with an effective recovery rate of $85.80 \%$. The number of valid samples was more than ten times the number of questions in the questionnaire (28 questions), which conforms with the empirical criteria proposed by Kline $[35,44]$. The basic information of the recovered 429 valid questionnaires was categorized. The proportions of both male and female respondents in this survey are approximately 50\%, and no extreme gender difference is prevalent. The respondents are primarily between 20 and 40 years old (approximately 61\%). Most of the respondents possess a bachelor's degree in terms of the level of education (approximately $38 \%$ ). The monthly income of the respondents is mainly in the 3000-5000 Yuan range (approximately $43 \%$ ). Approximately $32 \%$ of respondents have a private car. The specific personal attributes data are detailed in Table 2.

4.2. Measurement Model Evaluation. The CFA results of the measurement model are listed in Tables 3 and 4 . The CR values of all latent variables are greater than 0.7 , indicating that the internal consistency or isomorphism between the measurement variables of the same latent variable is good. As reflected by the measurement variables, the construct (latent trait) has a good consistency, and the reliability is at the "moderate" level. The factor loading coefficients of all measurement variables are greater than 0.6, and the AVE values are greater than 0.5 , indicating that the measurement variables have a high degree of internal correlation, which can effectively reflect the latent traits of the latent variables. Further, the proportion of variance explained by the latent variable is much higher than that explained by the measurement error, thus indicating that the measurement model has good convergent validity. The AVE value of each of the latent variables is always greater than the PCC value between this latent variable and the other ones, indicating that there are significant differences between the constructs of different latent variables, and the model has good discriminant validity. It can be observed that both the reliability and validity of the model have satisfied the requirements, thereby showing that the model is of good internal quality.

4.3. Structural Model Evaluation. The overall goodness-of-fit test results of the model are listed in Table 5. All the goodness-of-fit evaluation indices reached the test criteria, indicating that the model has good adaptability and external quality. The standardized path coefficient $\beta$ can reflect the magnitude of the interaction between variables. The square multiple correlation (SMC) of the endogenous latent variables, namely, $R^{2}$, can reflect the explanatory power of the model. The standardized path analysis results of the structural model are presented in Table 6 and Figure 3.

The impact of each latent variable on $\mathrm{AI}$ is ranked from the highest to the lowest as follows: $\operatorname{PR}(\beta=-0.71, P<0.001)$, PT $(\beta=0.66, P<0.001), \quad$ PU $(\beta=0.65, P<0.001), \quad$ SN $(\beta=0.53, P<0.001), \mathrm{HM}(\beta=0.42, P<0.001)$, and PEU $(\beta=0.38, P<0.01)$. All the latent variables have shown a significant impact on the AI with a confidence interval of $95 \%$ (corresponding to $P<0.05$ ). The only exception is that $\mathrm{HM}$ did not present a significant impact on $\mathrm{PU}(\beta=0.23$, $P>0.05)$, and $P R$ has the most significant negative impact on PT $(\beta=-0.78, P<0.001)$ among all variables. Therefore, the research hypotheses pertaining to the latent variables, $\mathrm{H} 1-\mathrm{H} 10$ and $\mathrm{H} 12$, are supported, but $\mathrm{H} 11$ is rejected. In the model, the proportion of variance in AI that can be explained by all the other variables is $52 \%\left(R^{2}=0.52\right)$, which reaches the minimum standard of 0.4 proposed by Cohen et al. [45], and the model has a good interpretation ability.

\section{Discussion}

According to the results of the empirical analysis, the reliability and validity of the measurement model have reached a good level and the overall fit of the structural model has also reached the test criteria. The theoretical model constructed in this study has good internal and external quality. In the structural model, all research hypotheses have been verified, except for hypothesis H11, which is not supported. Overall, the newly added PR and PT variables in this study have the most significant influence on acceptance intention in the model, exceeding the influence of other variables in the model on acceptance intention. PEU has the weakest but most significant impact on acceptance intention; PR has a significant negative impact on PT and this negative impact is 
TABle 2: Description of questionnaire statistics $(N=429)$.

\begin{tabular}{|c|c|c|c|}
\hline Personal attribute & Classification & Sample size $(N)$ & Percentage \\
\hline \multirow{2}{*}{ Gender } & Male & 209 & $48.80 \%$ \\
\hline & Female & 220 & $51.20 \%$ \\
\hline \multirow{6}{*}{ Age (years) } & $<20$ & 27 & $6.37 \%$ \\
\hline & $20-30$ & 138 & $32.23 \%$ \\
\hline & $31-40$ & 125 & $29.16 \%$ \\
\hline & $41-50$ & 76 & $17.60 \%$ \\
\hline & $51-60$ & 34 & $7.99 \%$ \\
\hline & $>60$ & 29 & $6.65 \%$ \\
\hline \multirow{4}{*}{ Education level } & High school and below & 64 & $15.03 \%$ \\
\hline & College degree & 118 & $27.56 \%$ \\
\hline & Bachelor's degree & 164 & $38.26 \%$ \\
\hline & Master's degree and above & 82 & $19.15 \%$ \\
\hline \multirow{4}{*}{ Monthly income (yuan) } & $<3000$ yuan & 91 & $21.32 \%$ \\
\hline & $3000-5000$ yuan & 186 & $43.29 \%$ \\
\hline & 5000-10000 yuan & 108 & $25.18 \%$ \\
\hline & $>10000$ yuan & 44 & $10.21 \%$ \\
\hline \multirow{2}{*}{ Ownership of a private car } & Own a private car & 138 & $32.17 \%$ \\
\hline & Not own a private car & 291 & $67.83 \%$ \\
\hline
\end{tabular}

TABle 3: Analysis results of reliability and convergent validity.

\begin{tabular}{|c|c|c|c|c|}
\hline Latent variable & Item no. & Factor loading coefficient & $\mathrm{CR}$ & AVE \\
\hline \multirow{3}{*}{ PU } & PU1 & 0.79 & \multirow{3}{*}{0.798} & \multirow{3}{*}{0.568} \\
\hline & PU2 & 0.72 & & \\
\hline & PU3 & 0.75 & & \\
\hline \multirow{3}{*}{ PEU } & PEU1 & 0.71 & \multirow{3}{*}{0.778} & \multirow{3}{*}{0.538} \\
\hline & PEU2 & 0.74 & & \\
\hline & PEU3 & 0.75 & & \\
\hline \multirow{4}{*}{ PR } & PR1 & 0.66 & \multirow{4}{*}{0.839} & \multirow{4}{*}{0.572} \\
\hline & PR2 & 0.72 & & \\
\hline & PR3 & 0.92 & & \\
\hline & PR4 & 0.70 & & \\
\hline \multirow{3}{*}{ PT } & PT1 & 0.69 & \multirow{3}{*}{0.771} & \multirow{3}{*}{0.530} \\
\hline & PT2 & 0.64 & & \\
\hline & PT3 & 0.76 & & \\
\hline \multirow{3}{*}{ SN } & SN1 & 0.73 & \multirow{3}{*}{0.828} & \multirow{3}{*}{0.617} \\
\hline & SN2 & 0.84 & & \\
\hline & SN3 & 0.81 & & \\
\hline \multirow{3}{*}{$\mathrm{HM}$} & HM1 & 0.94 & \multirow{3}{*}{0.813} & \multirow{3}{*}{0.597} \\
\hline & HM2 & 0.70 & & \\
\hline & HM3 & 0.68 & & \\
\hline \multirow{3}{*}{ AI } & AI1 & 0.77 & \multirow{3}{*}{0.862} & \multirow{3}{*}{0.677} \\
\hline & AI2 & 0.90 & & \\
\hline & AI3 & 0.84 & & \\
\hline
\end{tabular}

also the strongest influence relationship among all the variables in the model; each variable of the model has a good ability to explain acceptance intention and the amount of variation explained by each variable reaches $52 \%$. The following is a comparative analysis of the influence of each variable in the research model on acceptance intention and previous studies, as well as the value of this research.

\subsection{Comparative Analysis with Previous Studies}

5.1.1. Impacts of $P U$ and PEU on AI. According to the evaluation results of the structural model, PU showed the third greatest impact on AI. It indicates that travelers pay more attention to the usefulness of travel information on social networks, and only when the travelers believe that the travel information is helpful to make travel decisions will 
TABLE 4: Analysis results of discriminant validity.

\begin{tabular}{|c|c|c|c|c|c|c|c|}
\hline & $\mathrm{PU}$ & PEU & PR & $\mathrm{PT}$ & SN & $\mathrm{HM}$ & $\mathrm{AI}$ \\
\hline $\mathrm{PU}$ & 0.893 & & & & & & \\
\hline PEU & 0.587 & 0.733 & & & & & \\
\hline PR & 0.415 & 0.488 & 0.756 & & & & \\
\hline $\mathrm{PT}$ & 0.507 & 0.452 & -0.648 & 0.728 & & & \\
\hline SN & 0.468 & 0.416 & 0.505 & 0.612 & 0.785 & & \\
\hline HM & 0.411 & 0.682 & 0.494 & 0.594 & 0.629 & 0.773 & \\
\hline AI & 0.594 & 0.451 & -0.529 & 0.525 & 0.581 & 0.587 & 0.823 \\
\hline CR & 0.798 & 0.778 & 0.839 & 0.771 & 0.828 & 0.813 & 0.862 \\
\hline AVE & 0.568 & 0.538 & 0.572 & 0.530 & 0.617 & 0.597 & 0.677 \\
\hline
\end{tabular}

Note. Values on the diagonal of the coefficient matrix in the table are the square roots of the AVE values, and values in the lower triangular matrix are the PCC between variables.

TABLE 5: Test results of goodness-of-fit.

\begin{tabular}{lccccc}
\hline Evaluation index & $\chi^{2} / \mathrm{d} f$ & CFI & TLI & RMSEA & SRMR \\
\hline Criterion & $(1,3)$ & $>0.90$ & $>0.90$ & $<0.08$ & $<0.08$ \\
Test value & 2.36 & 0.91 & 0.91 & 0.03 & 0.05 \\
\hline
\end{tabular}

TABLE 6: Standardized path analysis results of the structural model and test result of hypothesis.

\begin{tabular}{|c|c|c|c|c|c|}
\hline Hypotheses & Estimate & SE & $\mathrm{CR}$ & $P$ & Hypothesis test result \\
\hline $\mathrm{H} 1: \mathrm{PU} \longrightarrow \mathrm{AI}$ & 0.65 & 0.105 & 6.190 & $* * *$ & H1 supported \\
\hline $\mathrm{H} 2: \mathrm{PEU} \longrightarrow \mathrm{AI}$ & 0.38 & 0.081 & 4.691 & $* *$ & H2 supported \\
\hline $\mathrm{H} 3: \mathrm{PEU} \longrightarrow \mathrm{PU}$ & 0.31 & 0.066 & 4.697 & $* *$ & H3 supported \\
\hline $\mathrm{H} 4: \mathrm{PR} \longrightarrow \mathrm{AI}$ & -0.71 & 0.090 & -7.889 & $* * *$ & H4 supported \\
\hline $\mathrm{H} 5: \mathrm{PT} \longrightarrow \mathrm{AI}$ & 0.66 & 0.133 & 4.962 & $* * *$ & H5 supported \\
\hline H6: $\mathrm{PR} \longrightarrow \mathrm{PT}$ & -0.78 & 0.086 & -9.070 & $* * *$ & H6 supported \\
\hline $\mathrm{H} 7: \mathrm{SN} \longrightarrow \mathrm{AI}$ & 0.53 & 0.086 & 6.163 & $* * *$ & H7 supported \\
\hline $\mathrm{H} 8: \mathrm{SN} \longrightarrow \mathrm{PU}$ & 0.46 & 0.096 & 4.792 & $* *$ & H8 supported \\
\hline $\mathrm{H} 9: \mathrm{SN} \longrightarrow \mathrm{PR}$ & 0.48 & 0.102 & 4.706 & $* * *$ & H9 supported \\
\hline $\mathrm{H} 10: \mathrm{HM} \longrightarrow \mathrm{AI}$ & 0.42 & 0.092 & 4.565 & $* * *$ & H10 supported \\
\hline $\mathrm{H} 11: \mathrm{HM} \longrightarrow \mathrm{PU}$ & 0.23 & 0.194 & 1.186 & 0.076 & H11 rejected \\
\hline $\mathrm{H} 12: \mathrm{HM} \longrightarrow \mathrm{PEU}$ & 0.29 & 0.104 & 2.788 & $*$ & H12 supported \\
\hline
\end{tabular}

Note. Estimate represents the estimated value of the standardized path coefficient; SE represents the standard error term of the path coefficient; CR is the critical ratio, $\mathrm{CR}=$ estimate/SE, and a CR value greater than 1.96 indicates that a significance level of 0.05 has been reached; ${ }^{* * *}$ denotes $P<0.001,{ }^{* *}$ denotes $P<0.01$, and *denotes $P<0.05$.

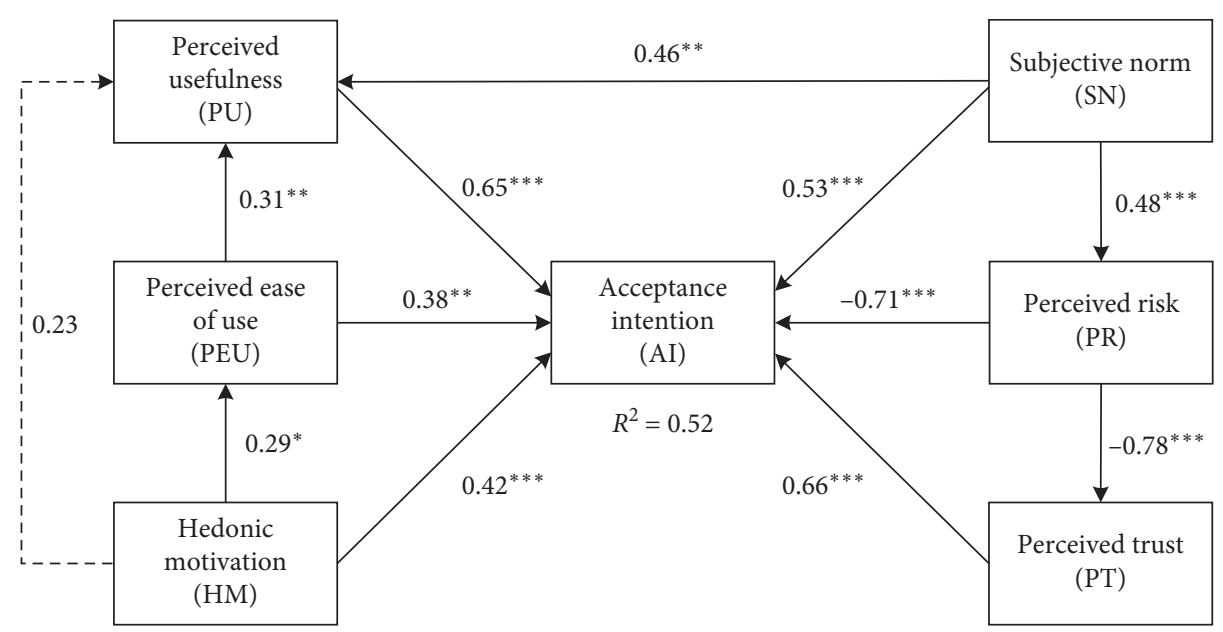

Figure 3: Analysis results of the structural model. Note. The solid arrows represent the paths with significant impacts, and the dotted arrow represents the path with insignificant impact; ${ }^{* * *}$ denotes $P<0.001,{ }^{* *}$ denotes $P<0.01$, and ${ }^{*}$ denotes $P<0.05$. 
they be willing to accept the travel information, which is consistent with the findings of Chung et al. [14]. Although the impact of PEU on AI is found to be small, it cannot be ignored. It is worth noting that PEU here is the ease of process using the social network media platform to obtain travel information, which indicates that the easier the use of social network media platforms to obtain travel information is, the easier the travelers will accept it. In the study of Bilgihan et al., it was pointed out that PEU has a decisive influence on the sharing behavior of travel information on social networks [11].

5.1.2. Impacts of $P R$ and PT on AI. In this study, PR showed the most significant impact on $\mathrm{AI}$, and it is a negative impact. This observation indicates that travelers pay special attention to the security of travel information on social networks, which shows typical risk avoidance. The higher the risk perceived by travelers regarding this travel information is, the less willing the travelers will be to accept it. Tseng and Wang also pointed out the negative impact of PR on the use of travel information [46]. PT showed the second greatest impact on AI, only after PR. It indicates that the influence of trust factors on AI is also critical. The greater the trust travelers have in travel information on social networks, the stronger their AIs will be. This observation can be mutually supported by the research conclusions of Berhanu and Raj [15] and Li et al. [47].

5.1.3. Impacts of $S N$ and $H M$ on AI. SN represents the impacts of the surrounding social groups (friends, colleagues, etc.) on the traveler's own behavioral decisions, and it showed the fourth greatest impact on AI. It indicates that if the traveler's surrounding social groups have a very strong AI of travel information on social networks, it will be easier for him/her to accept the information. This is similar to the research findings of Bilgihan et al. on travel information sharing behavior on social networks [11]. There is no other research that explores the relationship between $\mathrm{HM}$ and AI of travel information on social networks. However, in the field of technology acceptance research of information systems, it has been confirmed by Venkatesh et al. that HM has a decisive impact on the intention to use information systems [28]. This study found that the impact of HM on AI of travel information on social networks exists but is not very strong, only higher than the impact of PEU on AI. It indicates that travelers do not pay much attention to the level of fun and pleasure involved in using the social network media platform to obtain travel information.

5.2. Research Value. This research explores the factors that influence travelers' acceptance intention of travel information on social networks. The data analysis results indicate the issues that traffic managers and travelers should pay attention to when publishing and sharing travel information on social media. PR and PT have the strongest influence on acceptance intentions. Therefore, when traffic managers and travelers publish travel information on social networks, they should first ensure that the information is easy and quick to obtain, the information is updated in a timely and accurate manner, and the information cost is clear, to resolve the information recipient's concerns regarding the timeliness, accuracy, and cost. Simultaneously, attention should be paid to increasing the intensity of user and operator entry review and behavior supervision to ensure the security of obtaining and sharing travel information on social networks to increase the trust of travelers and make them more willing to accept travel information. PU and PEU also have a certain degree of influence on the acceptance intention, which shows that the practical value of travel information in social networks should be guaranteed and PEU should be improved from the aspects of information acquisition and software operation methods. Only useful and easy-to-use travel information will be readily accepted and used by travelers. The influence of HM and SN on acceptance intention is also significant, indicating that when travel information is released on social networks, attention should be paid to increase the interest in the information content and enhance its attraction to the user. In addition, relevant management departments should pay attention to publicity and promotion to increase the popularity of travel information on social networks and the scope of dissemination and focus on improving the usage efficiency of information through using the social influence power between users.

\section{Conclusions}

The purpose of this study is to explore the influencing factors that affect the travelers' AI of travel information on social networks and the relationships between the various factors. The research results can be expected to provide preliminary references for further research in this field. In the current study, it is found that PU, PEU, PR, PT, SN, and HM all have a significant impact on AI. Moreover, the impacts of the newly added variables-PR and PT-on the AI of travel information on social networks are especially prominent. It can be considered that the model constructed in this study demonstrates good applicability for the research of AI of travel information on social networks.

This study has two levels of significance in terms of theoretical enlightenment and practical application reference. At the theoretical level, this study extends the TAM and incorporates new variables that can characterize the features of travel information on social networks. An empirical basis has been provided for the effective combination of the PR, PT, HM, and TAM. The theoretical analysis methods have been enriched in the research field of technology acceptance. At the practical application level, this study explored the influencing factors that could affect the travelers' AI of travel information on social networks. It can provide reference opinions for social network media platform managers or users to publish travel information content and for the government to issue management policies for travel information on social networks. For example, it is found in this study that PR and PT are the most important influencing factors for AI. Therefore, the release, dissemination, and management of travel information on 
social networks should strive to solve the traveler's risk concerns about the safety and personal privacy of travel information, enhance its accuracy and timeliness, and increase the trust of travelers to improve their AI.

However, this study inevitably has limitations that need to be resolved. First, the explanatory power of the current research model for the AI of travel information on social networks is $52 \%$, which indicates that the model has not fully captured the influencing factors on the public AI. Whether other influencing factors in the research field of technology acceptance (such as perceived value and facilitating conditions) would significantly affect AI still requires further exploration. Second, the main purpose of this study is to explore the relationship between the degree of interpretation of the constructed extension model on the intention to accept travel information on social networks and the analysis of various influencing factors. Therefore, it does not consider the moderating effect of demographic attributes, such as traveler's gender, age, and education level, on the intention to accept travel information on social networks; this can be confirmed by subsequent studies in the future.

\section{Data Availability}

The data used to support the findings of this study are available from the corresponding author upon request.

\section{Conflicts of Interest}

The authors declare that there are no conflicts of interest regarding the publication of this paper.

\section{Acknowledgments}

This research was funded by the Western Project of the National Social Science Fund of China, grant no. 17XGL009, and the Humanities and Social Sciences Research Planning Project of Chongqing Municipal Education Commission, grant no. 19SKGH208.

\section{References}

[1] K. Simon, Global Digital Report of 2020, We Are Social and Hootsuite, London, UK, 2020.

[2] Z. Xiang and U. Gretzel, "Role of social media in online travel information search," Tourism Management, vol. 31, no. 2, pp. 179-188, 2010.

[3] K.-H. Yoo and U. Gretzel, "Influence of personality on travelrelated consumer-generated media creationfluence of personality on travel-related consumer-generated media creation," Computers in Human Behavior, vol. 27, no. 2, pp. 609-621, 2011.

[4] N. Chung and C. Koo, "The use of social media in travel information search," Telematics and Informatics, vol. 32, no. 2, pp. 215-229, 2015.

[5] T. H. Rashidi, A. Abbasi, M. Maghrebi, S. Hasan, and T. S. Waller, "Exploring the capacity of social media data for modelling travel behaviour: opportunities and challenges," Transportation Research Part C: Emerging Technologies, vol. 75, pp. 197-211, 2017.
[6] E. Ampt and T. Ruiz, "Workshop synthesis: use of social media, social networks and qualitative approaches as innovative ways to collect and enrich travel data," Transportation Research Procedia, vol. 32, no. 1, pp. 93-98, 2018.

[7] A. M. Munar and J. K. S. Jacobsen, "Motivations for sharing tourism experiences through social media," Tourism Management, vol. 43, pp. 46-54, 2014.

[8] J. De Abreu E Silva, J. De Oña, and S. Gasparovic, "The relation between travel behaviour, ICT usage and social networks. the design of a web based survey," Transportation Research Procedia, vol. 24, pp. 515-522, 2017.

[9] N. A. Khan, M. A. Habib, and S. Jamal, "Investigation of weekend travel, social networking and transport-support application usage: a structural equation modeling approach," Procedia Computer Science, vol. 130, pp. 510-517, 2018.

[10] X. Chen and H. Deng, "A correlation analysis of information use, social networks and cooperation consciousness in travel behaviors," Transportation Research Part F: Traffic Psychology and Behaviour, vol. 62, pp. 819-832, 2019.

[11] A. Bilgihan, A. Barreda, F. Okumus, and K. Nusair, "Consumer perception of knowledge-sharing in travel-related online social networks," Tourism Management, vol. 52, pp. 287-296, 2016.

[12] T. Oliveira, B. Araujo, and C. Tam, "Why do people share their travel experiences on social media?" Tourism Management, vol. 78, Article ID 104041, 2020.

[13] T. Oliveira, B. Araujo, and C. Tam, "Dataset for understanding why people share their travel experiences on social media: structural equation model analysis," Data in Brief, vol. 30, Article ID 105447, 2020.

[14] N. Chung, H. Han, and C. Koo, "Adoption of travel information in user-generated content on social media: the moderating effect of social presence," Behaviour \& Information Technology, vol. 34, no. 9, pp. 902-919, 2015.

[15] K. Berhanu and S. Raj, "The trustworthiness of travel and tourism information sources of social media: perspectives of international tourists visiting Ethiopia," Heliyon, vol. 6, no. 3, Article ID e03439, 2020.

[16] F. D. Davis, "Perceived usefulness, perceived ease of use, and user acceptance of information technology," MIS Quarterly, vol. 13, no. 3, pp. 319-340, 1989.

[17] J.-M. Tsai, M.-J. Cheng, H.-H. Tsai, S.-W. Hung, and Y.-L. Chen, "Acceptance and resistance of telehealth: the perspective of dual-factor concepts in technology adoption," International Journal of Information Management, vol. 49, pp. 34-44, 2019.

[18] R. Scherer, F. Siddiq, and J. Tondeur, "The technology acceptance model (TAM): a meta-analytic structural equation modeling approach to explaining teachers' adoption of digital technology in education," Computers \& Education, vol. 128, pp. 13-35, 2019.

[19] T. Zhang, D. Tao, X. Qu et al., "Automated vehicle acceptance in China: social influence and initial trust are key determinants," Transportation Research Part C: Emerging Technologies, vol. 112, pp. 220-233, 2020.

[20] Y. Lu, S. Papagiannidis, and E. Alamanos, "Exploring the emotional antecedents and outcomes of technology acceptance," Computers in Human Behavior, vol. 90, pp. 153-169, 2019.

[21] R. A. Bauer, "Consumer behavior as risk taking," in Dynamic Marketing for a Changing World, Proceedings of the 43rd, R. S. Hancock, Ed., pp. 389-398, American Marketing Association: CHI, Chicago, IL, USA, 1960. 
[22] R. C. Mayer, J. H. Davis, and F. D. Schoorman, "An integrative model of organizational trust," The Academy of Management Review, vol. 20, no. 3, pp. 709-734, 1995.

[23] D. Gefen, E. Karahanna, and D. W. Straub, "Trust and TAM in online shopping: an integrated model," MIS Quarterly, vol. 27, no. 1, pp. 51-90, 2003.

[24] M. Fishbein and I. Ajzen, "Belief, attitude, intention and behaviour: an introduction to theory and research," Philosophy \& Rhetoric, vol. 41, no. 4, pp. 842-844, 1980.

[25] V. Venkatesh and F. D. Davis, "A theoretical extension of the technology acceptance model: four longitudinal field studies," Management Science, vol. 46, no. 2, pp. 186-204, 2000.

[26] L. D. Kaczmarek, "Hedonic motivation," in Encyclopedia of Personality and Individual Differences, V. Zeigler-Hill and T. Shackelford, Eds., Springer, Cham, Switzerland, 2017.

[27] S. A. Brown and V. Venkatesh, "Model of adoption of technology in households: a baseline model test and extension incorporating household life cycle," MIS Quarterly, vol. 29, no. 3, pp. 399-426, 2005.

[28] V. Venkatesh, J. Y. L. Thong, and X. Xu, "Consumer acceptance and use of information technology: extending the unified theory of acceptance and use of technology," MIS Quarterly, vol. 36, no. 1, pp. 157-178, 2012.

[29] S. A. Nikou and A. A. Economides, "Mobile-based assessment: investigating the factors that influence behavioral intention to use," Computers \& Education, vol. 109, pp. 56-73, 2017.

[30] J.-K. Liang, T. Eccarius, and C.-C. Lu, "Investigating factors that affect the intention to use shared parking: a case study of Taipei city," Transportation Research Part A: Policy and Practice, vol. 130, pp. 799-812, 2019.

[31] A. A. Abdallah, B. Abdullah, N. P. Rana, T. Kuttimani, and Y. K. Dwivedi, "Examining adoption of mobile internet in Saudi Arabia: extending tam with perceived enjoyment, innovativeness and trust," Technology in Society, vol. 55, pp. 100-110, 2018.

[32] J. R. Priester, "The use of structural equation models in consumer psychology: a methodological dialogue on its contributions, cautions, and concerns," Journal of Consumer Psychology, vol. 20, no. 2, pp. 205-207, 2010.

[33] H. Camgoz-Akdag and S. Zaim, "Education: a comparative structural equation modeling study," Procedia-Social and Behavioral Sciences, vol. 47, pp. 874-880, 2012.

[34] F. Boccia and P. Sarnacchiaro, "Structural equation model for the evaluation of social initiatives on customer behaviour," Procedia Economics and Finance, vol. 17, pp. 211-220, 2014.

[35] R. B. Kline, Principles and Practice of Structural Equation Modeling, Guilford Press, New York, NY, USA, 2nd edition, 2005.

[36] K. A. Bollen, Structural Equations with Latent Variables, Wiley, New York, NY, USA, 1989.

[37] C. Fornell and D. F. Larcker, "Evaluating structural equation models with unobservable variables and measurement error," Journal of Marketing Research, vol. 18, no. 1, pp. 39-50, 1981.

[38] R. P. Bagozzi and Y. Yi, "On the evaluation of structural equation models," Journal of the Academy of Marketing Science, vol. 16, no. 1, pp. 74-94, 1988.

[39] J. F. J. Hair, R. E. J. Anderson, R. L. Tatham, and W. C. Black, Multivariate Data Analysis, Prentice-Hall, Upper Saddle River, NJ, USA, 5th edition, 1998.

[40] M. R. A. Hamid, W. Saml, and M. H. Mohmad-Sldek, "Discriminant validity assessment: use of Fornell \& Larcker criterion versus HIMT criterion," Journal of Physics Conference Series, vol. 890, no. 1, Article ID 012163, 2017.
[41] D. Iacobucci, "Structural equations modeling: fit indices, sample size, and advanced topics," Journal of Consumer Psychology, vol. 20, no. 1, pp. 90-98, 2010.

[42] T. Niemand and R. Mai, "Flexible cutoff values for fit indices in the evaluation of structural equation models," Journal of the Academy of Marketing Science, vol. 46, no. 6, pp. 1148-1172, 2018.

[43] L. T. Hu and P. M. Bentler, "Cutoff criteria for fit indexes in covariance structure analysis: conventional criteria versus new alternatives," Structural Equation Modeling: A Multidisciplinary Journal, vol. 6, no. 1, pp. 1-55, 1999.

[44] J. J. Hoogland and A. Boomsma, "Robustness studies in covariance structure modeling," Sociological Methods \& Research, vol. 26, no. 3, pp. 329-367, 1998.

[45] P. Cohen, S. G. West, and L. S. Aiken, Applied Multiple Regression/Correlation Analysis for the Behavioral Sciences, Psychology Press, London, UK, 2014.

[46] S.-Y. Tseng and C.-N. Wang, "Perceived risk influence on dual-route information adoption processes on travel websites," Journal of Business Research, vol. 69, no. 6, pp. 2289-2296, 2016.

[47] S. R. Li, Y. X. Ong, and N. Ito, "Credibility in question: travel information adoption among Chinese consumers in Canada and Singapore," in Information and Communication Technologies in Tourism 2020, J. Neidhardt and W. Wörndl, Eds., Springer, Cham, Switzerland, 2020. 